\title{
BMJ Open Use of guideline-recommended drug therapy in patients undergoing percutaneous coronary intervention for stable coronary heart disease in Germany: a multilevel analysis of nationwide routine data
}

\author{
Julia Frank-Tewaag (D) , , 1,2,3 Julian Bleek, ${ }^{4}$ Dirk Horenkamp-Sonntag, ${ }^{5}$ \\ Ursula Marschall, ${ }^{6}$ Uwe Zeymer, ${ }^{7}$ Norbert Donner-Banzhoff, ${ }^{8}$ Leonie Sundmacher ${ }^{9}$
}

To cite: Frank-Tewaag J, Bleek J, Horenkamp-Sonntag D, et al. Use of guidelinerecommended drug therapy in patients undergoing percutaneous coronary intervention for stable coronary heart disease in Germany: a multilevel analysis of nationwide routine data. BMJ Open 2020;10:e042886. doi:10.1136/ bmjopen-2020-042886

- Prepublication history and additional materials for this paper is available online. To view these files, please visit the journal online (http://dx.doi. org/10.1136/bmjopen-2020042886).

Received 17 July 2020

Revised 15 September 2020

Accepted 25 November 2020

Check for updates

(c) Author(s) (or their employer(s)) 2020. Re-use permitted under CC BY-NC. No commercial re-use. See rights and permissions. Published by BMJ.

For numbered affiliations see end of article.

Correspondence to Julia Frank-Tewaag; J.FrankTewaag@Imu.de

\section{ABSTRACT}

Objectives To determine the prescription of guideline recommended drug therapy in patients with stable coronary heart disease (sCHD) prior to percutaneous coronary intervention (PCI) in Germany and to examine the role of patient characteristics and features of regional healthcare supply in a multilevel model. Design Secondary data analysis of factors associated with the prescription of guideline recommended drug therapy using a multilevel model to analyse regionallevel effects, over and above the effects of patient-level demographic and health status.

Setting Office-based prescriptions in the year prior to the invasive procedure.

Participants A linked nationwide dataset from Germany's three largest statutory health insurance funds of all patients receiving $\mathrm{PCl}$ in the year 2016.

Main outcome measures Patients' odds of receiving optimal medical therapy and symptom-oriented therapy within 1 year prior to $\mathrm{PCl}$.

Results $68.6 \%$ of patients received at least one lipidlowering drug and one symptom-oriented therapy prior to $\mathrm{PCl} .43 .6 \%$ received at least two agents to control their symptoms. Patients who received treatment in accordance with the recommendations had a greater number of diagnosed risk factors, a more severe history of cardiac disease and used a higher volume of ambulatory office-based physician services. The prescriptions prevalence for the symptom-oriented therapies differed significantly between eastern and western Germany, with a higher prevalence in the eastern districts.

Conclusions Guidelines can only provide decision-making corridors, and the applicability of recommendations must always be assessed on a case by case basis. Nevertheless, our analysis indicates that the prevalence of prescriptions in routine practice is subject to substantial variation and that conservative therapy options are not fully exhausted prior to $\mathrm{PCl}$. This suggests that there might be room for improvement in the care of patients with SCHD.
Strengths and limitations of this study

- We used a linked, comprehensive, nationwide data set with patient-level information on prescriptions, hospital and ambulatory care from the three largest statutory health insurers in Germany, covering approximately 42.5 million individuals.

- We examined the role of the health care supply and regional characteristics, in addition to patient-level demographic and health status variables, on the prescription guideline recommended drug therapy.

- The large number of patients examined in the analysis allowed us to generate reliable estimates on the regional level.

- The prescription data do not include drugs prescribed and administered in hospitals and of overto-counter drugs.

- Because a prescription was recorded only in cases where a patient redeemed it, a low prescription prevalence may be due to poor implementation of treatment recommendations on the part of providers or a lack of adherence or treatment discontinuation on the part of patients.

\section{BACKGROUND}

In addition to lifestyle-modifying measures, drug therapy has become the mainstay of treatment in patients with stable coronary heart disease (sCHD). Comprehensive metaanalyses, ${ }^{12}$ the Clinical Outcomes Utilizing Revascularization and Aggressive Drug Evaluation (COURAGE) study ${ }^{3}$ and the recent landmark International Study of Comparative Health Effectiveness with Medical and Invasive Approaches (ISCHEMIA) trial $^{4} 5$ provide strong evidence that coronary revascularisation is not associated with an improvement of the prognosis compared with optimal drug therapy in this patient group. Current 
clinical guidelines recommend drug therapy as the initial approach to managing patients with sCHD, with percutaneous coronary intervention (PCI) reserved for patients whose symptoms persist despite optimal medical therapy (OMT) ${ }^{6-8}$

The translation of these findings and recommendations into clinical practice, however, might be a subject for improvement. Studies in the $\mathrm{USA}^{9}$ and Canada ${ }^{10}$ looked at large samples of patients with sCHD who underwent elective PCI, and therefore, should generally have received drug therapy before this invasive intervention. They found, however, that the proportion of individuals in whom that had indeed been the case was disappointingly small. The authors of the Canadian study suggested several explanations for their findings, including an overestimation of the benefits of PCI among patients, the nonuniversal acceptance by doctors of the results of recent trials, or knowledge gaps among clinicians regarding appropriate management of patients with sCHD. ${ }^{10}$ According to a health technology assessment report by Gorenoi et al, about two-thirds of PCIs are unnecessary because the symptoms could also be managed in a conservative manner using drug therapy. ${ }^{11}$ While there have been no equivalent studies of patients who underwent PCI in Germany, researchers have investigated the use of drug therapy after hospitalisation or after acute cardiovascular events ${ }^{12-17}$ and found that it has been suboptimal in patient groups that would have benefited from it according to current treatment guidelines.

The aim of the present study is to contribute to this evidence base by drawing on a nationwide set of routine healthcare data to assess whether patients who underwent PCI received guideline-recommended drug therapy during the year before they underwent the invasive procedure. To do so, we obtained and linked nationwide data from three large statutory health insurers (SHIs). First, we examined whether clinical practice in Germany reflects the recommendations of the German and European guidelines among patients with sCHD and if there might be opportunities to improve their care. Subsequently, we estimated a multilevel model to examine the influence of patient characteristics, and the supply of healthcare services in different geographies, on the use of drug therapy because the literature suggests that both can play an important role in this regard. ${ }^{16-30}$

\section{METHOD \\ Database}

Our analysis was based on a set of linked billing data from the SHIs AOK, BARMER and Techniker Krankenkasse from the years 2014-2016. The dataset comprises patients who underwent PCI in 2016 as an inpatient, outpatient or in an office-based practice. We supplemented the dataset with the anatomical therapeutic chemistry (ATC) classification by linking it to the WIdO database of pharmaceutical products. ${ }^{31}$ Moreover, we added the characteristics of regional healthcare supply from the INKAR database ${ }^{32}$ and the National Association of Statutory Health Insurance Physicians (Kassenärztliche Bundesvereinigung, $\mathrm{KBV}) .{ }^{32} 33$

\section{Patient population}

We included patients in the study if they were 18 years of age or older and had received PCI in 2016 as an inpatient, an outpatient or in an office-based practice (EBM: 34292, OPS: 8-837). To limit the population to individuals with sCHD, our main analysis included only patients treated for chronic ischaemic heart disease (I25), stable angina pectoris (I20.8 and I20.9) or chest pain (R07) at the time of PCI. To avoid any impact from recent coronary events, we excluded all patients who had undergone PCI or coronary artery bypass graft surgery (CABG) in 2015 or had had an acute myocardial infraction (MI) within the year before the index PCI. Furthermore, we considered only those patients who had been insured for at least 360 days in the years before the index PCI and without missing information. Patients who died during or after the PCI were not excluded.

In addition, to assess possible differences in the prescription prevalence depending on the indication, we undertook a sensitivity analysis (1) that included patients with unstable angina pectoris (I20.0 and I20.1). The main analysis comprised patients who had an inpatient or office-based diagnosis of CHD (ICD I20-I25, inpatient primary or secondary diagnosis or confirmed office-based diagnosis in at least two quarters) during the period from 2014 to the billing quarter prior to the index PCI. This restriction presupposes that patients had contact with inpatient medical services at least once or had seen an office-based physician more than once. Therefore, in a second sensitivity analysis (2), we examined patients without a confirmed diagnosis of CHD in the observation period.

\section{Prescription prevalence and measures of guideline- concordant care}

Our analysis considers the recommendations of both the German and European guidelines on the management of sCHD. ${ }^{6-8}$ Using data on prescriptions, we divided patients into users and non-users of the recommended drug therapies in the year before PCI using the ATC classification (see online supplemental file 1, table 1 for the ATC codes is used). Lastly, we grouped the classes of substances, according to the guideline recommendations, as preferred or alternative treatments and classified these as having been prescribed with the aim of improving a patient's prognosis or relieving his or her symptoms. For the purpose of our analysis, we considered beta-blockers as belonging to the latter of these categories even though they can also enhance prognosis (see figure 1).

Based on these classifications, we defined 'OMT' as a combined measure that reflected the guideline recommendations. For this measure, we defined a patient as a user if, within the year before PCI, he or she had had received at least one prescription for a lipid-lowering 
Table 1 Individual characteristics and prescription prevalence

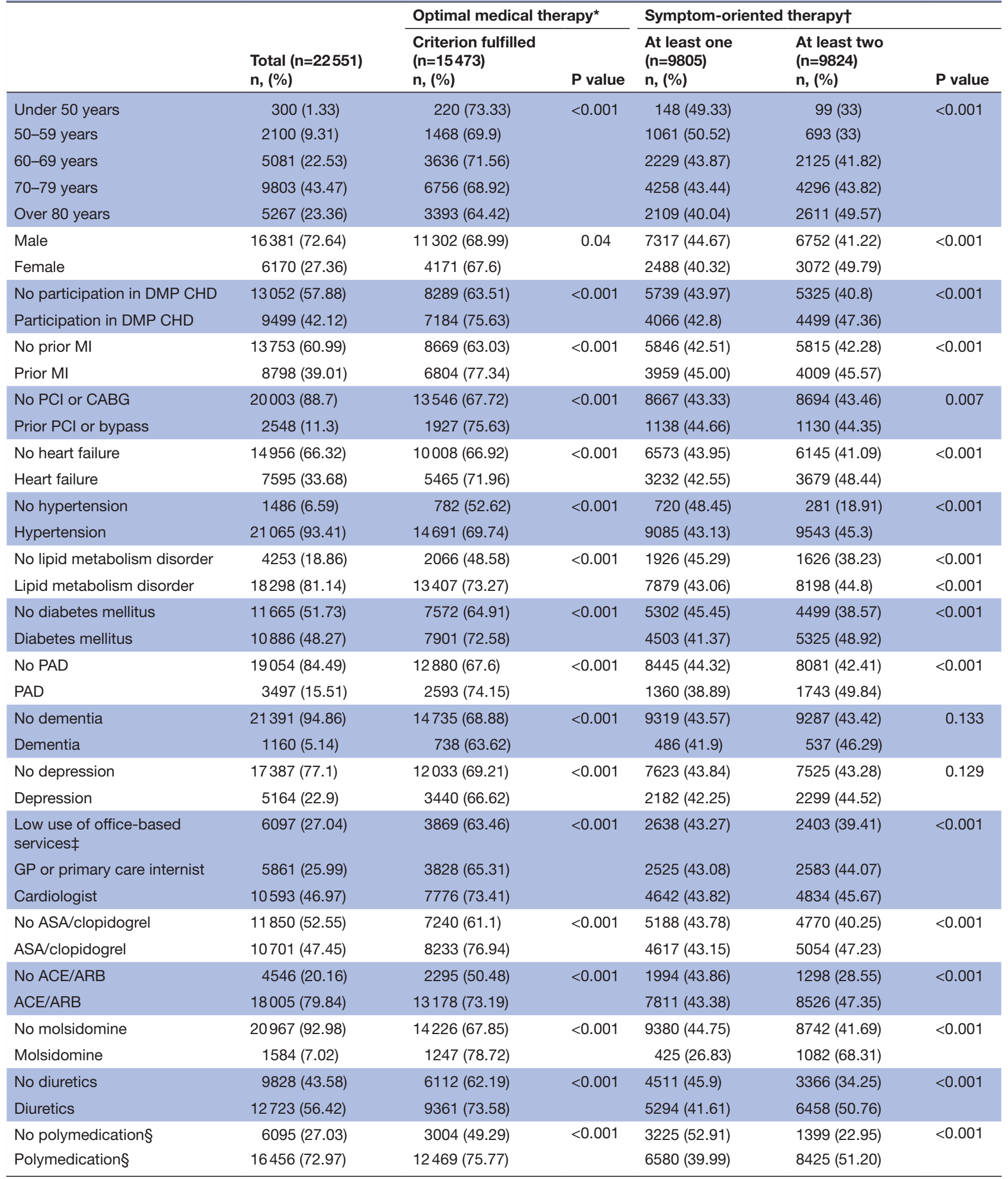




\begin{tabular}{|c|c|c|c|c|c|}
\hline \multirow[b]{2}{*}{$\begin{array}{l}\text { Total }(n=22551) \\
n,(\%)\end{array}$} & \multirow{2}{*}{\multicolumn{2}{|c|}{$\begin{array}{l}\text { Optimal medical therapy* } \\
\text { Criterion fulfilled } \\
\text { ( } n=15473)\end{array}$}} & \multicolumn{3}{|c|}{ Symptom-oriented therapy† } \\
\hline & & & $\begin{array}{l}\text { At least one } \\
(n=9805) \\
n,(\%)\end{array}$ & $\begin{array}{l}\text { At least two } \\
(\mathrm{n}=9824) \\
\mathrm{n},(\%)\end{array}$ & $P$ value \\
\hline
\end{tabular}

${ }^{*}$ At least one lipid-lowering and one symptom-oriented therapy.

†At least two classes of drugs or combination.

$\ddagger$ Patients with fewer than two visits to a physician per year.

§Patients with more than five long-term (DDD lasting for 90 days or more) prescriptions according to ATC code.

ACE, angiotensin-converting enzyme; ARB, angiotensin II receptor blockers; ASA, acetylsalicylic acid; ATC, Anatomical Therapeutic Chemistry;

CABG, coronary artery bypass graft; CHD, coronary heart disease; DMP, disease management program; GP, general practitioner; MI, myocardial

infraction; PAD, peripheral arterial disease; $\mathrm{PCl}$, percutaneous coronary intervention.

agent (ie, a statin, fibrate, anion exchanger or cholesterol absorption inhibitor) and at least one prescription for a recommended symptomatic therapy (ie, a beta-blocker, calcium channel blocker, ivabradine, ranolazine or organic nitrate).

Because (1) the prescription prevalence of antiplatelet agents could not be reliably estimated due to the over-tocounter (OTC) availability of acetylsalicylic acid (ASA), (2) molsidomine is not recommended as an alternative to nitrates and (3) the indication for the use of angiotensinconverting enzyme (ACE) inhibitors and angiotensin II receptor blockers (ARB) could not be clearly derived, we did not consider the use of these agents in our analysis of the two combined measures. We do, however, present the prescription prevalence of these and of other active substances with intersecting indications descriptively.

Because the symptomatic relief of chest pain plays an important role, especially when PCI is considered as a

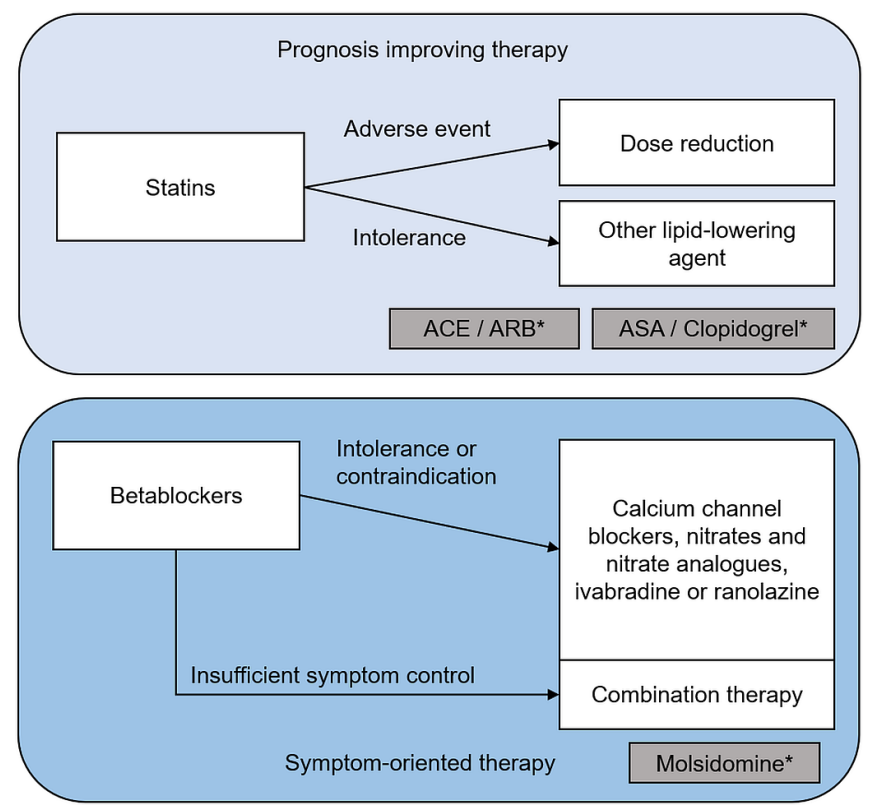

Figure 1 Systematisation of drug therapy based on guideline recommendations. For the purpose of our analysis, beta-blockers were considered as belonging to the symptomoriented therapy. ${ }^{*}$ Not included in the combined endpoints. ACE, angiotensin-converting enzyme; ARB, angiotensin II receptor blockers; ASA, acetylsalicylic acid. subsequent treatment option, we examined symptomoriented therapy alone in a separate analysis and paid special attention to whether the options for conservative treatment had been exhausted. For this purpose, we classified patients as users if they received a prescription for at least two classes of symptom-oriented therapy within the year before PCI.

\section{Study variables}

There are many reasons why patients may fail to receive a recommended drug therapy or not follow a recommended regimen. Obstacles can exist at the level of the patient, the provider and the health system. We, therefore, undertook a multilevel analysis to examine how patient-specific and regional health services supply factors might affect the use of the recommended drug therapies. In doing so, we considered factors for which there is evidence of an association with poor use of guidelinerecommended drug therapies or high rates of treatment

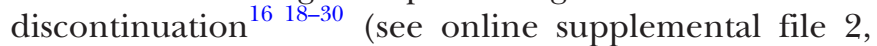
for the description of the variable selection and table 1 for the International Classification of Diseases, 10th Revision,German Modification (ICD-10-GM) codes that were used).

\section{Statistics}

We presented prescription prevalence in a descriptive manner. The patient characteristics were stratified according to drug therapy and compared using $\chi^{2}$ test. In a logistic regression model, we examined the influence of patient-specific study variables on prescription prevalence. Subsequently, within a multilevel model, we considered variation at the level of the administrative districts and examined the influence of the variables related to features of local healthcare supply. For the purpose of multilevel analysis, we mean centred age. We assessed the specific and general context effects by intraclass correlation coefficient (ICC), median OR (MOR), proportion change in variance (PCV), proportion of opposite odds (POOR), 80\%-interval OR $(80 \%$-IOR) and ROC AUC curve comparisons. We considered a $\mathrm{p}<0.05$ to be statistically significant. Analyses were performed with StataSE V.15.

\section{Patient and public involvement}

Patients and public were not involved. 


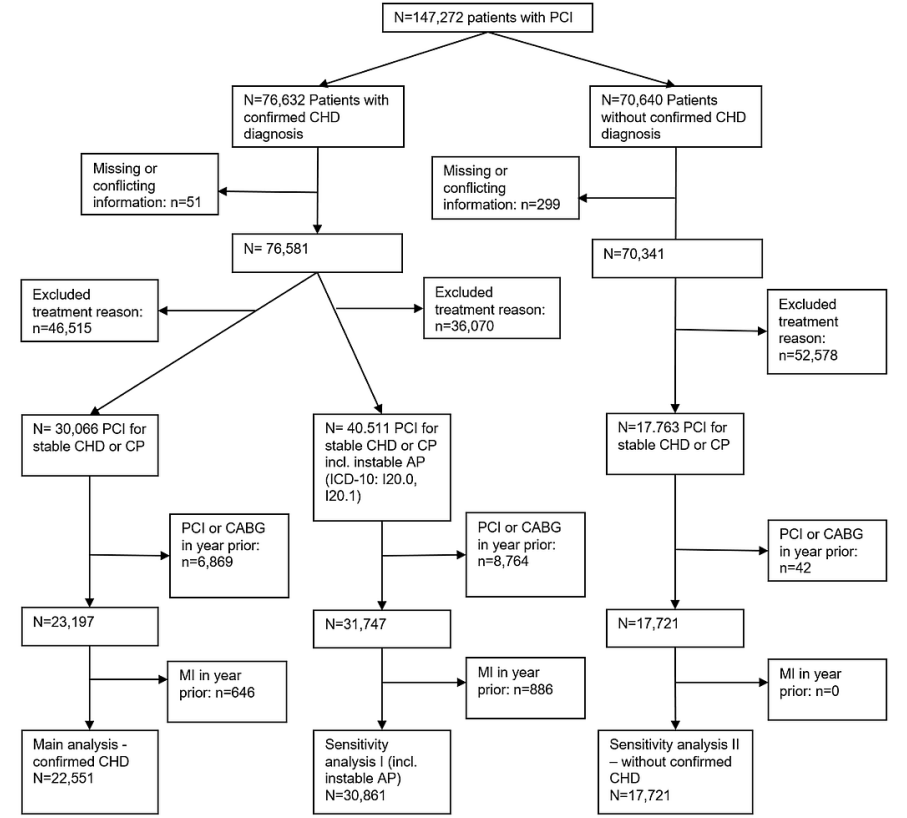

Figure 2 Selection of the patient population. AP, angina pertoris; CABG, coronary artery bypass graft; CHD, coronary heart disease; CP, chest pain; ICD, International Classification of Diseases; Ml, myocardial infarction; N, number of patients; PCI, percutaneous coronary intervention.

\section{RESULTS}

\section{Study sample}

The dataset comprised nationwide linked billing data from approximately 42.5 million individuals. In 2016, a total of 147272 patients in the dataset received at least one PCI. The selection yielded a study population for the main analysis consisting of 22551 patients. In addition, we performed a sensitivity analysis (1) including patients with unstable angina pectoris and a further sensitivity analysis (2) with patients who did not have a confirmed CHD diagnosis prior to the index PCI (see figure 2).

\section{Prescription prevalence}

Within the year before the index PCI in 2016, the criterion of OMT was met in $68.61 \%$ of patients. $25.40 \%$ were prescribed only one of these therapies, and 5.99\% received no OMT-prescriptions. Of the 17044 (75.58\%) patients who received a prescription for a lipid-lowering drug, the majority (98.04\%) were prescribed a statin. Of the $19629(87.04 \%)$ patients who received a prescription for at least one of the symptom-oriented therapies, $43.56 \%$ were prescribed at least two symptom-oriented drugs. The majority of patients received a prescription for a beta-blocker $(75.36 \%), 33.87 \%$ a prescription for a calcium channel blocker and $26.02 \%$ a prescription for a regimen consisting of both agents. $26.47 \%$ were prescribed an organic nitrate. Ivabradine was prescribed in fewer than $2 \%$, ranolazine in just over $5 \%$ of patients (see figure 3 and table 1 for individual characteristics and prescription prevalence).

Sensitivity analysis including patients with unstable angina pectoris revealed minor differences in prescription prevalence. Patients without a confirmed diagnosis of CHD prior to PCI had a lower prescription prevalence for all drug classes. The criterion of OMT was fulfilled in $31.13 \%$ of these patients. Seventy-six per cent received a prescription for at least one of the two therapies, and $24.00 \%$ receive no OMT-prescriptions. $63.81 \%$ of the patients received a prescription for at least one of the symptom-oriented therapies, and $24.07 \%$ of the patients

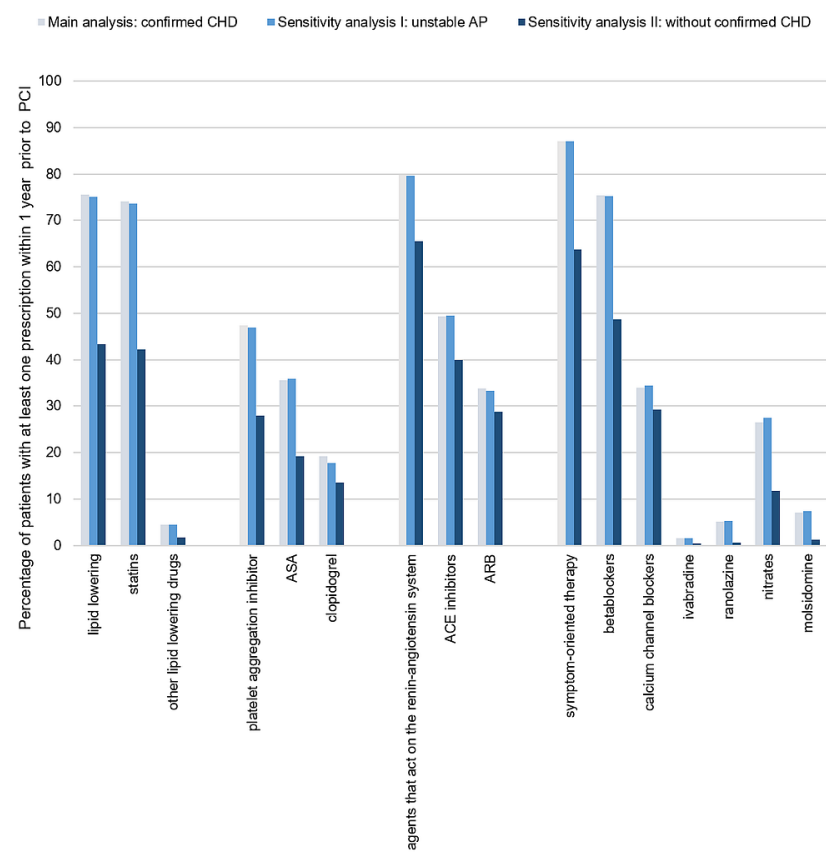

Figure 3 Prescription prevalence of the active substances. Percentage of patients with at least one prescription within 1 year prior to $\mathrm{PCl}$. ACE, angiotensin-converting enzyme; AP, angina pertoris; ARB, angiotensin II receptor blockers; ASA, acetylsalicylic acid; CHD, coronary heart disease; PCl, percutaneous coronary intervention. 
received a prescription for at least two classes of these drugs.

\section{Optimal medical therapy}

Patients with a previous MI, a diagnosed lipid metabolism disorder, previous CABG or PCI, diabetes mellitus, $\mathrm{PAD}$, heart failure or hypertension had higher odds of receiving the OMT within the year before the index PCI (see table 2). Above average age and a diagnosis of dementia or depression were associated with lower odds of receiving a prescription for the OMT. The sex of the patient showed no significant association with such prescriptions. Although symptom-oriented therapy was prescribed more frequently in women, the proportion of men who were prescribed a lipid-lowering drug was $76.54 \%$ compared with $73.03 \%$ in women $(p<0.001)$. Participation in a disease management program (DMP) for CHD was associated with a higher odds of being prescribed the OMT. Patients who made at least two visits to the general practitioner (GP) or primary care internist per year or who had an additional contact with a cardiologist had higher odds of being prescribed the OMT or primary care internist per year or who had an additional contact with a cardiologist had higher odds of being prescribed the OMT compared with patients who made fewer visits. The variables at the regional level showed no statistically significant effect. Although likelihood-ratio tests suggest that the differences between the districts is not zero, the ICC points to a low correlation within each of the districts. The measures of the general and specific context effects suggest that the variables characterising the regional healthcare supply had little explanatory power and accounted for only a small proportion $(\mathrm{PCV}=4.9 \%)$ of variance at the district level.

\section{Symptom-oriented therapy}

Prior MI, above average age, female gender and diagnosed risk factors and comorbidities, were associated with a higher odds of receiving a prescription for symptomoriented therapy in the year before the index PCI. Enrolment in a DMP for CHD, regular visits to the GP or primary care internist and additional contact with a cardiologist also showed a positive association compared with patients who used fewer healthcare services. A previous PCI or CABG, or a diagnosis of dementia or depression showed no significant influence on such prescriptions. The variables we considered for regional healthcare supply also showed no significant association. However, patients in eastern Germany had higher odds of being prescribed symptom-oriented therapy after considering patient characteristics. The comparison of eastern and western German districts suggests that there is, on average, a positive association for the former, with an OR of 1.19 (95\% CI 1.09 to 1.30). However, unmodelled interdistrict variability remained, which is reflected in the broad $80 \%$ IOR(95\% CI 0.86 to 1.64$)$. The POOR was moderate $(24.5 \%)$. The model, including the regional variables, explains $14.20 \%$ of the variance at district level.
Table 2 Multilevel model of influencing factors

\begin{tabular}{|c|c|c|c|c|}
\hline & \multicolumn{2}{|c|}{$\begin{array}{l}\text { Optimal medical } \\
\text { therapyt }\end{array}$} & \multicolumn{2}{|c|}{$\begin{array}{l}\text { Symptom-oriented } \\
\text { therapy }\end{array}$} \\
\hline & OR & $95 \% \mathrm{Cl}$ & OR & $95 \% \mathrm{Cl}$ \\
\hline \multicolumn{5}{|l|}{ Individual level } \\
\hline Age§ & 0.99 & $(0.98 \text { to } 0.99)^{\star *}$ & 1.01 & $(1.01 \text { to } 1.02)^{\star \star}$ \\
\hline Female & 1.06 & (0.99 to 1.13 ) & 1.37 & $(1.29 \text { to } 1.46)^{\star \star}$ \\
\hline DMP CHD & 1.58 & $(1.49 \text { to } 1.69)^{\star \star}$ & 1.23 & $(1.17 \text { to } 1.31)^{\star \star}$ \\
\hline Prior MI & 1.71 & $(1.60 \text { to } 1.82)^{\star \star}$ & 1.13 & $(1.07 \text { to } 1.20)^{\star \star}$ \\
\hline $\begin{array}{l}\text { Previous PCl/ } \\
\text { CABG }\end{array}$ & 1.23 & $(1.11 \text { to } 1.36)^{\star \star}$ & 1.01 & (0.92 to 1.10$)$ \\
\hline Heart failure & 1.08 & $(1.01 \text { to } 1.15)^{*}$ & 1.13 & $(1.07 \text { to } 1.20)^{\star \star}$ \\
\hline Hypertension & 1.66 & $(1.48 \text { to } 1.86)^{\star *}$ & 2.8 & $(2.44 \text { to } 3.21)^{\star \star}$ \\
\hline $\begin{array}{l}\text { Lipid metabolism } \\
\text { disorder }\end{array}$ & 2.46 & $(2.29 \text { to } 2.64)^{\star \star}$ & 1.15 & $(1.07 \text { to } 1.24)^{\star \star}$ \\
\hline Diabetes mellitus & 1.34 & $(1.26 \text { to } 1.42)^{\star *}$ & 1.38 & $(1.30 \text { to } 1.46)^{\star \star}$ \\
\hline PAD & 1.22 & $(1.12 \text { to } 1.33)^{\star \star}$ & 1.23 & $(1.14 \text { to } 1.32)^{\star \star}$ \\
\hline Dementia & 0.75 & $(0.66 \text { to } 0.86)^{\star \star}$ & 0.89 & (0.78 to 1.00$)$ \\
\hline Depression & 0.81 & $(0.76 \text { to } 0.88)^{\star \star}$ & 0.97 & (0.90 to 1.03 ) \\
\hline $\begin{array}{l}\text { GP or primary } \\
\text { care internist }\end{array}$ & 1.17 & $(1.08 \text { to } 1.27)^{\star \star}$ & 1.16 & $(1.08 \text { to } 1.26)^{\star *}$ \\
\hline Cardiologist & 1.47 & $(1.37 \text { to } 1.59)^{\star *}$ & 1.19 & $(1.11 \text { to } 1.27)^{\star \star}$ \\
\hline \multicolumn{5}{|l|}{ District level } \\
\hline $\begin{array}{l}\text { Pharmacies } \\
\text { per } 100000 \\
\text { inhabitants }\end{array}$ & 1 & (0.99 to 1.01 ) & 1.01 & (1.00 to 1.02 ) \\
\hline $\begin{array}{l}\text { GPs per } 100000 \\
\text { inhabitants }\end{array}$ & 1 & (0.99 to 1.01 ) & 1 & (0.99 to 1.00 ) \\
\hline $\begin{array}{l}\text { Internists } \\
\text { per } 100000 \\
\text { inhabitants }\end{array}$ & 1 & (1.00 to 1.01$)$ & 1 & (1.00 to 1.01$)$ \\
\hline $\begin{array}{l}\text { No of cases per } \\
\text { GP }\end{array}$ & 1 & (1.00 to 1.00$)$ & 1 & (1.00 to 1.00$)$ \\
\hline $\begin{array}{l}\text { No of cases per } \\
\text { internist }\end{array}$ & 1 & (1.00 to 1.00$)$ & 1 & (1.00 to 1.00$)$ \\
\hline Eastern Germany & 1.01 & (0.91 to 1.11$)$ & 1.19 & $(1.09 \text { to } 1.30)^{\star *}$ \\
\hline Constant & 0.28 & $(0.18 \text { to } 0.43)^{\star \star}$ & 0.12 & $(0.08 \text { to } 0.17)^{\star \star}$ \\
\hline $\begin{array}{l}\text { Variance of } \\
\text { districts }\end{array}$ & 0.04 & (0.02 to 0.06$)$ & 0.03 & (0.02 to 0.05 ) \\
\hline
\end{tabular}

${ }^{*} \mathrm{P}<0.05,{ }^{* *} \mathrm{p}<0.001$.

†At least one lipid-lowering and one symptom-oriented therapy. $\ddagger$ At least two classes of drugs or combination.

§Mean centred.

CABG, coronary artery bypass graft surgery; CHD, coronary heart disease; DMP, disease management program; GP, general practitioner; MI, myocardial infraction; PAD, peripheral arterial disease; $\mathrm{PCl}$, percutaneous coronary intervention.

Considering the patient characteristics and the multilevel structure, the MOR is 1.20 , or 1.18 if the district variables are included-that is, if a person moves to another district with a higher prescription likelihood, their risk of getting a prescription in median increases 1.20 or 1.18 times. 


\section{DISCUSSION}

Using a comprehensive set of nationwide routine data, the present study is the first to analyse patterns of use of guideline-recommended drug therapies among patients with sCHD in Germany in the time before they undergo PCI. The study also explores the association of these patterns with characteristics of regional healthcare supply and patient characteristics.

Although the European and German guidelines ${ }^{6-8}$ recommend drug therapy in patients with sCHD, our findings suggest that the recommendations are only fulfilled to a moderate degree that and there is substantial variation in how they are being implemented in Germany. In general, patients in our sample who received treatment in accordance with these recommendations were those who had a greater number of diagnosed risk factors and comorbidities and a more severe history of cardiac disease compared with patients who did not.

The associations observed in our analysis are consistent with the results of the Canadian study except that Garg et al observed a weak positive association in men. ${ }^{10}$ While we found that the use of symptom-oriented therapy in women was more frequent, gender showed no significant association with the OMT. This can be attributed to the lower prescription prevalence of statins in women in our sample, which is consistent with the results of a study on secondary prevention in CHD in Germany ${ }^{34}$ and with the findings of the EUROASPIRE IV and V surveys. ${ }^{13} 17$ We found that patients with diagnosed depression, above average age and diagnosed dementia have lower odds of receiving the OMT. It might, therefore, be useful to pay special attention in consultations with these patients when discussing, reviewing and agreeing on individual treatment plans.

The volume of ambulatory office-based services used by patients and of care provided by GPs and additional visits to cardiologists showed a positive association with the prescription of OMT. However, the variables included at the district level showed no discernible influence on the prevalence of OMT prescriptions.

The prevalence of prescriptions for the symptomoriented therapies differed significantly between eastern and western Germany, with a higher prevalence in the eastern districts. These results are consistent with those found in a study in patients with heart failure, which also suggest an east-west gradient in the use of beta-blocker therapy. ${ }^{35}$ These differences could be due to several factors, such as different patient preferences, historical differences in service providers' experience, preferences regarding the prescription, differences in drug budgets or variations in the market penetration of certain drugs. The role of the physician in the implementation of prevention guidelines for CHD and barriers to their implementation was studied by Reiner et al. The authors found that, although most physicians believe that guidelines are useful and necessary, $11.9 \%$ of primary care physicians, $7.0 \%$ of internists and $4.8 \%$ of cardiologists prefer to rely on their own personal experience. ${ }^{36}$
Moreover, the frequency of PCI varies widely within Germany, ${ }^{37-39}$ which suggests that the observed differences might reflect varying preferences in the use of invasive therapies.

Looking at patients regardless of whether they had a confirmed diagnosis of CHD, we found a prescription prevalence for most drug classes that was lower than that seen by Borden $e t a l$ in the USA and Garg $e t a l$ in Canada, with the exception of ACE inhibitors/ARB and beta-blockers. ${ }^{910}$ In the USA, $62.6 \%$ of these patients received a beta-blocker compared with $56.9 \%$ in Canada and $63.61 \%$ in Germany. While $64.3 \%$ of patients in Canada and the USA received a statin, the percentage in Germany was $60.10 \%$. Compared with the Canadian study, the proportion of patients receiving prescriptions was lower by $6.94 \%$ for calcium channel blockers, $3.45 \%$ for nitrates. It should be noted, however, that the observation period for measuring prescription prevalence in the two other studies was shorter than in ours, the composition of their patient sample may have differed and the combined measures they used are not directly comparable to those used in our analysis because they are based on different definitions.

The EUROASPIRE cross-sectional surveys have evaluated guideline implementation in European countries and found that, a large majority of patients with documented CHD, fail to achieve the therapeutic targets. When comparing the most recent results for Germany with those for patients with known CHD in our study, we find that the proportion of patients receiving lipid lowering medication was 12\% lower in our analysis than the proportion reported in EUROASPIRE $\mathrm{V}^{17}$ and the proportion receiving statins $7 \%$ lower compared with EUROASPIRE IV. ${ }^{13}$ Similarly the prescription prevalence we found for beta-blockers and for ACE inhibitors/ARB was lower than the proportion reported for Germany in EUROASPIRE IV, by $8 \%$ and $2 \%$, respectively. It should be noted, however, that the patient's sample of the EUROASPIRE surveys differs to the one in our analysis, because patients with documented CHD were recruited following hospitalisation. Zhao $e t a t^{40}$ have investigated medication use in patients with documented CHD in Europe, Asia and the Middle East and found substantial variations between regions and countries. The proportion of medication use the authors reported for Europe were higher than those found in our study with exception of calcium antagonist and ARBs. Again, it has to be noted that the patient sample differs to the one in our study, because participants were recruited from cardiology outpatient clinics in participating centres.

Because the results of our study may be considered as real-world evidence reflecting current routine practice, as opposed to observations made in clinical trials with strict control of drug regimens and selected patient populations, it is not surprising that the medication use reported after 5 years in the COURAGE study ${ }^{41}$ and after 1 year in the ISCHEMIA trial ${ }^{42}$ were higher than the prescription prevalence found in our analysis. 


\section{LIMITATIONS}

This study has several important limitations. First, our prescription data do not include drugs prescribed and administered in hospitals, ${ }^{43}$ which could lead to an underestimation of prescription prevalence. Second, because we could not rule out the OTC use of ASA, we expected the prevalence of its use to be underestimated. ${ }^{44}$ Third, because prescription data in Germany are passed on from the pharmacies to health insurers, a prescription was recorded only in cases where a patient redeemed it. Thus, a low prescription prevalence may be due to poor implementation of treatment recommendations on the part of providers or a lack of adherence or treatment discontinuation on the part of patients. Fourth, the drug therapies included in our model are not disease specific, and physicians' decisions to prescribe them may have been influenced by patients' comorbidities. This can lead to an overestimation of the prescription prevalence attributable to the CHD diagnosis. Fifth, our analysis does not consider intolerance or contraindications. Although we take account of the fact that the guidelines recommend alternatives, we cannot exclude the possibility that in certain cases both the preferred and alternative therapies were not prescribed because both were contraindicated. Sixth, the coding behaviour of physicians influences the documented diagnoses and there may be regional and specialty-specific differences in the coding. This can lead to a misclassification of patients in the study sample and subgroups. Lastly, our model does not consider the supply of care in surrounding districts and therefore only allows conclusions to be drawn about the impact of healthcare supply in a patient's district of residence. If care supply for the surrounding districts plays an important role, this will not be reflected in our findings.

\section{CONCLUSION}

The present analysis is the first to provide insights into the patterns of use of drug therapy prior to PCI among patients with sCHD in Germany while taking patient characteristics and characteristics of regional healthcare supply into account. We found substantial variation in the prescription of guideline-recommended drug therapies for this patient group in routine practice and that the conservative therapy options are not fully exhausted prior to PCI. Although our study was not designed to determine whether poor guideline implementation is the cause of this variation, our findings can be used to formulate hypotheses to be used in further research on this topic and that there might be room for improvement in the care of patients with sCHD in Germany.

\footnotetext{
Author affiliations

${ }^{1}$ Department of Health Services Management, Munich School of Management, Ludwig-Maximilians-University Munich, Munich, Germany

${ }^{2}$ Institute for Medical Information Processing, Biometry, and Epidemiology, LudwigMaximilians-University Munich, Munich, Germany

${ }^{3}$ Pettenkofer School of Public Health, Munich, Germany

${ }^{4}$ AOK Bundesverband, Berlin, Germany
}

${ }^{5}$ Techniker Krankenkasse, Hamburg, Germany

${ }^{6}$ BARMER, Wuppertal, Germany

${ }^{7}$ Stiftung Institut für Herzinfarktforschung, Ludwigshafen, Germany

${ }^{8}$ Department of General Practice/Family Medicine, Philipps-University Marburg, Marburg, Germany

${ }^{9}$ Chair of Health Economics, Technical University Munich, Munich, Germany

Acknowledgements We thank Sebastian Franke for providing access to the data through the trust center.

Contributors JF-T led the development of the study design and methodology, conducted the data analysis and wrote the initial a draft of the manuscript. LS, ND-B, UZ, JB, DH-S and UM contributed to the conception of the work, critically reviewed and revised the draft for important intellectual content and contributed to the interpretation of the results.

Funding This study (01VSF16048) was funded by the innovation fund of the Federal Joint Committee (G-BA).

Competing interests $\mathrm{JB}$ is employed by the AOK Bundesverband, UM by the BARMER, DH-S by the TK. UZ reports personal fees from Astra Zeneca, Bayer, BMS, Daiichi Sankyo, Novartis, Sanofi, Amgen, Trommsdorf, Medicines Company, outside the submitted work. JF-T, ND-B and LS have nothing to declare.

Patient consent for publication Not required.

Ethics approval This study exclusively used anonymised billing data was therefore deemed exempt from ethics review and informed consent.

Provenance and peer review Not commissioned; externally peer reviewed.

Data availability statement Data may be obtained from a third party and are not publicly available. The routine data analysed in this study are available from the statutory health insurances TK, AOK and BARMER, but restrictions apply to the availability of the data, which were used under licence for the current study and are not publicly available. To fulfil the legal requirements to obtain the data, researchers must obtain permission for a specific research question from the German Federal (Social) Insurance Office. Additionally, researchers must conclude a contract with the statutory health insurer regarding data access. The study must also be approved by the data protection officer both at the statutory health insurer and the research institute as well as the local ethics committee.

Supplemental material This content has been supplied by the author(s). It has not been vetted by BMJ Publishing Group Limited (BMJ) and may not have been peer-reviewed. Any opinions or recommendations discussed are solely those of the author(s) and are not endorsed by BMJ. BMJ disclaims all liability and responsibility arising from any reliance placed on the content. Where the content includes any translated material, BMJ does not warrant the accuracy and reliability of the translations (including but not limited to local regulations, clinical guidelines, terminology, drug names and drug dosages), and is not responsible for any error and/or omissions arising from translation and adaptation or otherwise.

Open access This is an open access article distributed in accordance with the Creative Commons Attribution Non Commercial (CC BY-NC 4.0) license, which permits others to distribute, remix, adapt, build upon this work non-commercially, and license their derivative works on different terms, provided the original work is properly cited, appropriate credit is given, any changes made indicated, and the use is non-commercial. See: http://creativecommons.org/licenses/by-nc/4.0/.

ORCID iD

Julia Frank-Tewaag http://orcid.org/0000-0001-7881-1338

\section{REFERENCES}

1 Katritsis DG, loannidis JPA. Percutaneous coronary intervention versus conservative therapy in nonacute coronary artery disease: a meta-analysis. Circulation 2005;111:2906-12.

2 Bangalore S, Maron DJ, Stone GW, et al. Routine revascularization versus initial medical therapy for stable ischemic heart disease: a systematic review and meta-analysis of randomized trials. Circulation 2020;142:841-57.

3 Boden WE, O'Rourke RA, Teo KK, et al. Optimal medical therapy with or without $\mathrm{PCl}$ for stable coronary disease. N Engl J Med 2007;356:1503-16.

4 Hochman J, ed. International study of comparative health effectiveness with medical and invasive approaches (ISCHEMIA): primary report of clinical outcomes. American Heart Association 
Annual Scientific Sessions (AHA 2019). Philadelphia, PA: American Heart Association, 2019.

5 Maron DJ, Hochman JS, Reynolds HR, et al. Initial invasive or conservative strategy for stable coronary disease. $N$ Engl J Med 2020;382:1395-407.

6 BÄK, KBV, AWMF. Nationale VersorgungsLeitlinie Chronische KHK Langfassung, 2014.

7 BÄK, KBV, AWMF. Nationale VersorgungsLeitlinie Chronische KHK Langfassung, 2016.

8 Task Force M, Montalescot G, Sechtem U, et al. 2013 ESC guidelines on the management of stable coronary artery disease. Eur Heart $J$ 2013;34:2949-3003.

9 Borden WB, Redberg RF, Mushlin Al, et al. Patterns and intensity of medical therapy in patients undergoing percutaneous coronary intervention. JAMA 2011;305:1882-9.

10 Garg P, Wijeysundera HC, Yun L, et al. Practice patterns and trends in the use of medical therapy in patients undergoing percutaneous coronary intervention in Ontario. J Am Heart Assoc 2014;3 doi:10.1161/JAHA.114.000882

11 Gorenoi V, Schönermark MP, Hagen A. Percutaneous coronary intervention with optimal medical therapy vs. optimal medical therapy alone for patients with stable angina pectoris. GMS Health Technol Assess 2011;7:Doc07.

12 Mangiapane S, Busse R. Prescription prevalence and continuing medication use for secondary prevention after myocardial infarction: the reality of care revealed by claims data analysis. Dtsch Arztebl Int 2011;108:856-62.

13 Reiner Ž, De Backer G, Fras Z, et al. Lipid lowering drug therapy in patients with coronary heart disease from 24 European countries-Findings from the EUROASPIRE IV survey. Atherosclerosis 2016;246:243-50.

14 Salzwedel A, Völler H, Reibis R, et al. [Regional aspects in treatment of patients with acute myocardial infarction in the North-East of Germany]. Dtsch Med Wochenschr 2018;143:e51-8.

15 Snaterse M, Khatibi S, Scholte Op Reimer WJM, et al. [Secondary prevention of coronary heart disease: results of Euroaspire IV]. Ned Tijdschr Geneeskd 2017;161:D643.

16 Zeymer U, Teilnehmer AR, ATKA-Register-Teilnehmer. [Secondary prevention in outpatients with coronary artery disease. Adherence with recommendations within 4 weeks after hospital discharge] Dtsch Med Wochenschr 2007;132:2367-70.

17 De Backer G, Jankowski P, Kotseva K, et al. Management of dyslipidaemia in patients with coronary heart disease: results from the ESC-EORP EUROASPIRE V survey in 27 countries. Atherosclerosis 2019;285:135-46.

18 Aikens JE, Piette JD. Diabetic patients' medication underuse, illness outcomes, and beliefs about antihyperglycemic and antihypertensive treatments. Diabetes Care 2009;32:19-24.

19 Chan DC, Shrank WH, Cutler D, et al. Patient, physician, and payment predictors of statin adherence. Med Care 2010;48:196-202.

20 Chapman RH, Benner JS, Petrilla AA, et al. Predictors of adherence with antihypertensive and lipid-lowering therapy. Arch Intern Med 2005;165:1147-52.

21 Desai NR, Choudhry NK. Impediments to adherence to post myocardial infarction medications. Curr Cardiol Rep 2013;15:322.

22 DiMatteo MR. Variations in patients' adherence to medical recommendations: a quantitative review of 50 years of research. Med Care 2004;42:200-9.

23 Fischer MA, Choudhry NK, Brill G, et al. Trouble getting started: predictors of primary medication nonadherence. Am J Med 2011:124:1081.e9-22.

24 Hirsh BJ, Smilowitz NR, Rosenson RS, et al. Utilization of and adherence to Guideline-Recommended lipid-lowering therapy after acute coronary syndrome: opportunities for improvement. J Am Coll Cardiol 2015;66:184-92.

25 Jiang W, Glassman A, Krishnan R, et al. Depression and ischemic heart disease: what have we learned so far and what must we do in the future? Am Heart J 2005;150:54-78.

26 Kulik A, Shrank WH, Levin R, et al. Adherence to statin therapy in elderly patients after hospitalization for coronary revascularization. Am J Cardiol 2011;107:1409-14.

27 Baumhäkel M, Müller U, Böhm M. Influence of gender of physicians and patients on guideline-recommended treatment of chronic heart failure in a cross-sectional study. Eur J Heart Fail 2009;11:299-303.

28 Arnold SV, Kosiborod M, Tang F, et al. Patterns of statin initiation, intensification, and maximization among patients hospitalized with an acute myocardial infarction. Circulation 2014;129:1303-9.

29 Zullig LL, Stechuchak KM, Goldstein KM, et al. Patient-reported medication adherence barriers among patients with cardiovascular risk factors. J Manag Care Spec Pharm 2015;21:479-85.

30 Zullig LL, Shaw RJ, Shah BR, et al. Patient-provider communication, self-reported medication adherence, and race in a postmyocardial infarction population. Patient Prefer Adherence 2015;9:311-8.

31 Wissenschaftlichen Instituts der AOK (WIdO). GKV-Arzneimittelindex des WIdO, 2017.

32 Indikatoren und Karten zur Raum- und Stadtentwicklung [online], 2015. Available: https://www.inkar.de/

33 Kassenärztliche Bundesvereinigung (KBV). Gesundheitsdaten Medizinische Versorgung, 2015.

$34 \mathrm{Knopf} \mathrm{H}$. [Drug usage of men and women with coronary heart disease. Results of the German Federal Health Survey 1998]. Bundesgesundheitsblatt Gesundheitsforschung Gesundheitsschutz 2004;47:1051-5.

35 Riens BB-F J. Leitliniengerechte therapie bei Herzinsuffizienz Zentralinstitut für die kassenärztliche Versorgung in Der Bundesrepublik Deutschland (Zi), 2014.

36 Reiner Z, Sonicki Z, Tedeschi-Reiner E. Physicians' perception, knowledge and awareness of cardiovascular risk factors and adherence to prevention guidelines: the PERCRO-DOC survey. Atherosclerosis 2010;213:598-603.

37 Drösler S. Regionale Unterschiede in Der Operationshäufigkeit Bewertung Der Daten und Handlungsbedarf. Krefeld, Germany, 2015.

38 Möckel M, Searle J, Indikation JE. Prognose und regionale Unterschiede Der Herzkatheterversorgung in Deutschland. Wissenschaftlichen Instituts Der AOK (WIdO), 2014.

39 OECD. Geographic variations in health care, 2014.

40 Zhao M, Cooney MT, Klipstein-Grobusch K, et al. Simplifying the audit of risk factor recording and control: a report from an international study in 11 countries. Eur J Prev Cardiol 2016;23:1202-10.

41 Maron DJ, Boden WE, O'Rourke RA, et al. Intensive multifactorial intervention for stable coronary artery disease: optimal medical therapy in the courage (clinical outcomes utilizing revascularization and aggressive drug evaluation) trial. J Am Coll Cardiol 2010;55:1348-58.

42 Newman JD, Alexander KP, Gu X, et al. Baseline predictors of low-density lipoprotein cholesterol and systolic blood pressure goal attainment after 1 year in the ischemia trial. Circ Cardiovasc Qual Outcomes 2019;12:e006002.

43 Neubauer SZ, Lange J.; A.; von der Schulenburg M. Grundlagen und Methoden von GKV-Routinedatenstudie. Hannover: Leibniz Universität, Center for Health Economics Research Hannover (CHERH), 2014.

44 Horenkamp-Sonntag D, Brüggenjürgen $\mathrm{B}$, Stasun U, et al. Validität von Arzneimitteldaten in GKV-Routinedaten. Monitor Versorgungsforschung 2017;17. 